\title{
Partial Mastectomy and M. Latissimus Dorsi Reconstruction for Radiation-induced Fibrosis After Breast-conserving Cancer Therapy
}

\author{
Albertus N. van Geel • Titia E. Lans • \\ Roel Haen - Rudi Tjong Joe Wai • \\ Marian B. E. Menke-Pluijmers
}

Published online: 17 December 2010

(C) The Author(s) 2010. This article is published with open access at Springerlink.com

\begin{abstract}
Background Patients with severe complaints of radiationinduced fibrosis after breast-conserving therapy and not responding to conservative therapy, were treated by partial mastectomy and $\mathrm{m}$. latissimus dorsi reconstruction.

Method To determine the feasibility and outcome of this approach, a retrospective study of nine patients was carried out.

Results After a mean follow-up of 46 months, eight of the nine patients experienced improvement of their complaints and shape of the breast. In only one case did the procedure fail, as evidenced by continuation of all complaints.

Conclusions Partial mastectomy and $\mathrm{m}$. latissimus dorsi reconstruction is the ultimate option in the treatment of radiation fibrosis. The procedure is safe with satisfying results.
\end{abstract}

\section{Introduction}

Cancer patients who undergo radiotherapy (RT) remain at lifelong risk of serious radiation-induced injury to normal tissue. This injury varies from fibrosis and radionecrosis to radiation-induced malignancies in the long term. In breast cancer about half of the patients are treated with breastconserving therapy (BCT), and this number seems to be increasing. A consequence of $\mathrm{BCT}$ is that postoperatively the remaining breast is irradiated, and a boost is given at the lumpectomy site [1]. These patients have a potential risk of radiation-related complications.

The complications are radiation dose and fractionation related, with a critical cut-off point of $50 \mathrm{~Gy}$ [2]. Other individual characteristics, such as diabetes and vascular disorders can contribute to the complication rate. In most cases the acute reaction will stay within acceptable limits and will return to normal within a few weeks. When the unfavorable effects persist for longer than 6 months, spontaneous improvement cannot be expected.

The layer of endothelium supplying the irradiated area starts to proliferate, resulting in a proliferative endarteritis. Most often noted in the capillaries, the endarteritis continues and interferes with the normal process of supplying blood to irradiated areas.

Significant problems arise during this clinical period as a consequence of chronic deterioration of the microvasculature and hypoperfusion, resulting in a mild radiationinduced fibrosis (RIF) in the boost area. With increasing tissue fibrosis and parenchymal degeneration, the compromised tissue has a lower resistance to stress factors. The ischemic tissue may survive without adequate blood supply for a long time, but a traumatic or infectious incident can trigger a series of events that may ultimately lead to extensive tissue death. 
The reported incidence of RIF is $5-15 \%$, probably underestimating its true incidence $[3,4]$. Studies report that about $45 \%$ of patients experience breast pain associated with RIF, ranging from frequent to constant pain in the irradiated area [5].

In published series it has been suggested that RIF stabilizes 2 years after RT to the breast [6]. Clinically, RIF is characterized by skin retraction, atrophy, and toughness to palpation, with consequent functional limitations, as well as by decreased tissue compliance. There will be a limited number of women with a progressive RIF over years; however, the exact number is unknown

Depending on the patient's complaints, conservative treatment can be administered; this can include systemic or topical medication (corticosteroids, anti-inflammatory agents, zinc, antioxidants), physiotherapy, or hyperbaric oxygen therapy. However, the results have been disappointing, and reports in the literature provide no evidence of benefit.

In some cases the RIF will become worse with persisting severe complaints, such as pain, deformity of the breast, discoloration, and repeated infections of the overlying skin.

When conservative treatment has failed and complaints remain, excision of the area with fibrosis or even mastectomy might be the ultimate treatment option. Excisional procedures often have numerous complications, however, because the surrounding tissue does not heal due to radiotherapyinduced ischemia. When attempting to graft to or rotate a flap to this area, surgeons must connect to tissue that is ischemic and hypoxic. The proper approach to overcoming this problem is to remove an extensive amount of breast tissue beyond the boost area, which results in a partial mastectomy (PM). Oncoplastic techniques can be used to close the defect, either with tissue displacement or tissue replacement.

The m. latissimus dorsi (LD) reconstruction is a widely used and safe reconstruction after partial or total mastectomy $[7,8]$. In irradiated areas it has also been proven to be safe [9]. The present study describes patients with serious complaints of RIF who were treated by a PM with LD reconstruction.

\section{Patients and methods}

In a retrospective study we describe nine patients with varying complaints after breast-conserving therapy followed by radiotherapy. When all conservative treatment failed, we operated on these patients with a partial mastectomy and reconstruction. The area with RIF was widely excised by a partial mastectomy and an immediate $\mathrm{m}$. latissimus dorsi musculocutaneous flap was used to maintain breast shape and volume. All data were collected retrospectively from the patient files. There was no structured inquiry for pain score, cosmetic outcome, or patient satisfaction.

Technical aspects of the operation

If feasible the operation was carried out in a side position, allowing a simultaneous procedure by surgeon (excision) and plastic surgeon (preparing the LD flap with a skin island). Based on physical examination, mammography, and magnetic resonance imaging (MRI), all fibrotic tissue was removed (partial mastectomy) including the scar, discolored skin, and at least the area of the radiotherapy boost. If the defect was too large for reconstruction with $\mathrm{LD}$, the breast was mobilized and rotated above the pectoral fascia to minimize the defect as it affected the volume of the LD. The muscle was fixed with soluble stitches and a suction drain was left in place. The LD skin island was sutured to the breast skin intracutaneously. All patients were treated with antibiotic prophylaxis.

\section{Results}

The patient characteristics are summarized in Table 1. All patients were women whose average age varied between 42 and 63 years, with a mean of 51 years. Radiotherapy (50 Gy) was administered in fractions of $2 \mathrm{~Gy}$, with a boost varying from 0 to $20 \mathrm{~Gy}$. In seven patients the RIF was located in the upper quadrants, five of them in the lateral upper quadrant. The main complaint was pain, sometimes combined with other symptoms like a burning sensation or loss of sensitivity, hyperpigmentation, or teleangiectasia. In two patients the main reason for treatment was dermatitis with recurrent mastitis. The mean time from BCT till PM and LD for RIF was 55 months $(41 / 2$ years), with a range of 27-89 months.

The mean size of the PM specimen was $465 \mathrm{~cm}^{3}$ $\left(230-750 \mathrm{~cm}^{3}\right)$, and the mean weight was $295 \mathrm{~g}(60$ $980 \mathrm{~g})$. Pathology reports of all excised tissue showed pathological changes, confirming the clinical diagnosis of RIF. In no patients breast cancer was found. There were no complications requiring surgical reintervention or leading to prolonged hospital stay. The follow-up after PM and LD was 13-113 months (mean: 46 months). One patient did not report any improvement of her complaints after PM and LD. This patient also suffered from multiple sclerosis and a recent cerebrovascular event, and ultimately a mastectomy was performed. The remaining eight patients were relieved of their most significant complaints. Postoperatively, none of the patients required painkillers, in contrast to the situation before the operation in every case (Table 2). All patients noticed significant improvement in their breast shape and compliance (Fig. 1). 
Table 1 Partial mastectomy and $\mathrm{m}$. latissimus dorsi reconstruction for radiationinduced fibrosis: patient characteristics

BCT breast-conserving therapy, LD latissimus dorsi flap reconstruction, PM partial mastectomy

${ }^{\text {a }}$ Whole breast irradiation and boost

b Interval between BCT and PM

c The two main complaints

Table 2 Partial mastectomy and $\mathrm{m}$. latissimus dorsi reconstruction for radiationinduced fibrosis: results

a (Almost) no complaints

b Slight complaints

c No change

d Time to mastectomy

Fig. 1 Two patients with radiation-induced fibrosis (left) and the result after partial mastectomy and $\mathrm{m}$. latissimus dorsi reconstruction (right)

\begin{tabular}{llllll}
\hline Patients & $\begin{array}{l}\text { Age at } \\
\text { BCT }\end{array}$ & $\begin{array}{l}\text { Radiation } \\
(\mathrm{Gy})^{\mathrm{a}}\end{array}$ & Quadrant & $\begin{array}{l}\text { Interval } \\
(\mathrm{months})\end{array}$ & $\begin{array}{l}\text { Indication for PM } \\
\text { and LD }^{\mathrm{c}}\end{array}$ \\
\hline 1 & 42 & $50+16$ & Upper lateral & 63 & Pain, hyperpigmentation \\
2 & 44 & $50+16$ & Upper central & 33 & Edema, pain \\
3 & 62 & $50+15$ & Lower lateral & 35 & Fibrosis, seroma \\
4 & 63 & 50 & Lower central & 73 & Pain, fibrosis \\
5 & 57 & $50+20$ & Upper lateral & 68 & Pain, hyperpigmentation \\
6 & 37 & 50 & Upper lateral & 27 & Recurrent mastitis, fibrosis \\
7 & 53 & $46+20$ & Upper lateral & 89 & Dermatitis, fibrosis \\
8 & 56 & $50+15$ & Upper lateral & 41 & Pain, fibrosis \\
9 & 49 & $50+20$ & Upper lateral & 69 & Fibrosis, pain \\
\hline
\end{tabular}

\begin{tabular}{lllccl}
\hline Patients & $\begin{array}{l}\text { Age at PM } \\
\text { and LD (years) }\end{array}$ & $\begin{array}{l}\text { Volume } \\
\left(\mathrm{cm}^{3}\right)\end{array}$ & Weight (g) & $\begin{array}{l}\text { Follow-up } \\
(\mathrm{months})\end{array}$ & Results after PM and LD \\
\hline 1 & 47 & $?$ & 60 & 24 & Pain, hyperpigmentation $^{\mathrm{a}}$ \\
2 & 46 & 540 & 280 & 13 & Edema, $^{\mathrm{a}}$ pain \\
3 & 65 & 360 & 180 & 47 & Fibrosis, seroma $^{\mathrm{a}}$ \\
4 & 68 & 670 & $?$ & 110 & Pain, fibrosis $^{\mathrm{a}}$ \\
5 & 63 & 360 & 300 & 86 & Pain, hyperpigmentation $^{\mathrm{a}}$ \\
6 & 39 & 270 & 160 & 113 & Recurrent mastitis, fibrosis $^{\mathrm{a}}$ \\
7 & 60 & 750 & 980 & 86 & Dermatitis, fibrosis $^{\mathrm{a}}$ \\
8 & 59 & 530 & 290 & 22 & Pain, $^{\mathrm{b}}$ fibrosis \\
9 & 55 & 230 & 210 & $25^{\mathrm{d}}$ & Fibrosis, $^{\mathrm{c}}$ pain $^{\mathrm{c}}$ \\
\hline
\end{tabular}
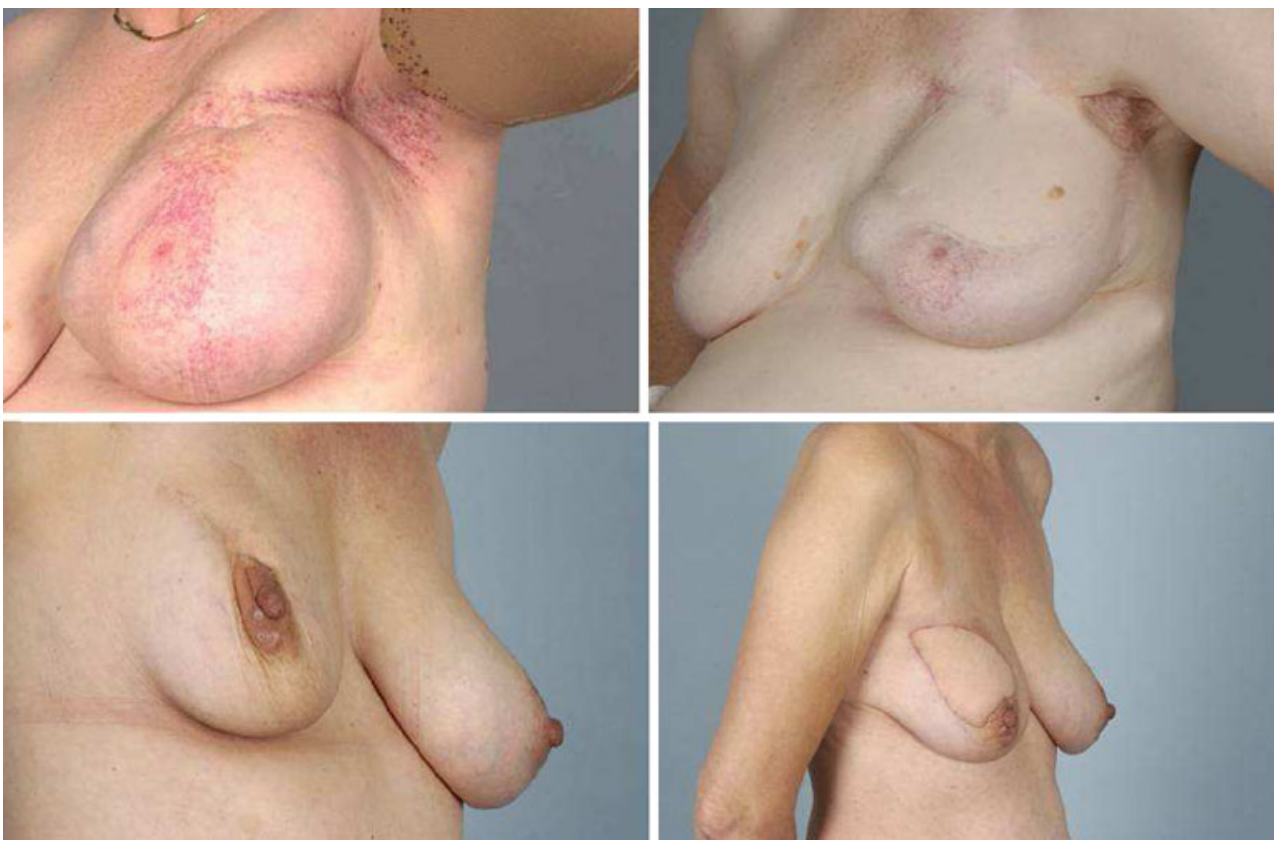

\section{Discussion}

Persisting complaints after breast-conserving surgery followed by radiotherapy represent a frequently reported clinical problem [3, 4]. Usually the complaints resolve without further treatment, but in some instances the adverse reaction of radiotherapy results in an irreversible RIF with associated with pain, erythema, and progressive edema or 
fibrosis, and complaints can persist for years. It is difficult to measure the degree of RIF with objective criteria. Compliance is the relationship between the force acting upon a tissue and transformation that is caused by that force. One way of measuring the compliance is by palpation [10], but it is subjective, with a great interobserver variability [11]. It is also possible to measure compliance with a more objective noninvasive tissue compliance meter (TCM) [12].

Common therapies consist of eliminating localized and general aggravating factors, and controlling acute and chronic inflammation with antibiotics and steroids. As progress has been made in understanding the pathophysiology of RIF lesions, different treatment strategies have been developed in clinical practice. These consist of antioxidants (vitamin-E [13], superoxide dismutase [14]), angiotensin-converting enzyme inhibitor (Captopril [14]), interferon-gamma [15], anti-inflammatory agents (Brufen [16]) and Pentoxifylline (Trental) [17]. However, all the studies of these strategies were performed in patients with acute radiation morbidity and the results, if any, were short-lived [13]. In a small randomized placebo-controlled study a six-month treatment with alpha-tocopherol (vitamin E) and pentoxifylline showed significant regression of RIF [18]; nevertheless, these results could not be confirmed by other investigators [19].

Hyperbaric oxygen therapy (HBOT) seems to be effective in the treatment of late radiation sequelae like pain, edema, erythema, and soft tissue necrosis. The HBOT allows tissue to be hyperoxygenated. By providing inhaled $100 \%$ oxygen under pressure, the arterial $\mathrm{P}_{\mathrm{O}_{2}} \mathrm{PO}_{2}$ is raised five to ten times above normal, which promotes healing. The hyperoxia stimulates fibroblast proliferation and collagen synthesis, which provide a matrix for angiogenesis at a faster rate, resulting in soft tissue repair. However, no randomized controlled trials are available to prove this theory [20].

When all conservative treatments have failed, it is necessary to excise the lesion extensively. A range of therapeutic options are available from which to choose the most reliable reconstruction technique to close the defect. Muscle and pedicled musculocutaneous flaps are reliable grafts due to their safety, their vascular, trophic and antiinfectious quality, and their excellent capacity of coverage.

A latissimus dorsi flap can be harvested without significant risks or side effects and can be used to fill a defect after resection of the area with RIF. This approach is known for its easy mobilization, high tissue vitality, and good cosmesis. The complication rate is low [7]. In our series we did not have complications while using LD reconstructions.

In one patient the PM and LD failed to solve the complaints based on RIF. In the other patients most of the problems were significantly improved with a mean followup of almost 4 years (Table 2).

\section{Conclusions}

A small number of patients treated with breast-conserving therapy and subsequent radiotherapy for breast cancer will suffer from radiation-induced fibrosis. Conservative treatment is the treatment of choice, sometimes lacking success at long-term follow-up. When associated problems interfere with the quality of life of patients, surgical removal of all affected tissue can help. A partial mastectomy, reconstructed with $\mathrm{m}$. latissimus dorsi proved to be a safe treatment option with satisfying results. Eight of our nine patients experienced improvement in associated complaints and in the shape of the breast.

Open Access This article is distributed under the terms of the Creative Commons Attribution Noncommercial License which permits any noncommercial use, distribution, and reproduction in any medium, provided the original author(s) and source are credited.

\section{References}

1. National Cancer Institute (2007) Cancer trends progress report2007. National Cancer Institute, Bethesda

2. Hill RP, Rodemann HP, Hendry JH et al (2001) Normal tissue radiobiology: from the laboratory to the clinic. Int J Radiat Oncol Biol Phys 49:353-365

3. Bentzen SM, Overgaard M, Thames HD (1989) Fractionation sensitivity of a functional endpoint: impaired shoulder movement after post-mastectomy radiotherapy. Int J Radiat Oncol Biol Phys 17:531-537

4. Overgaard M, Bentzen SM, Christensen JJ et al (1987) The value of the NSD formula in equation of acute and late radiation complications in normal tissue following 2 and 5 fractions per week in breast cancer patients treated with postmastectomy irradiation. Radiother Oncol 9:11

5. Fisher B, Anderson S, Redmond CK et al (1995) Reanalysis and results after 12 years of follow-up in a randomized clinical trial comparing total mastectomy with lumpectomy with or without irradiation in the treatment of breast cancer. $\mathrm{N}$ Engl $\mathrm{J}$ Med 333:1456-1461

6. Chen PY, Vicini FA, Benitez P et al (2006) Long-term cosmetic results and toxicity after accelerated partial-breast irradiation: a method of radiation delivery by interstitial brachytherapy for the treatment of early-stage breast carcinoma. Cancer 106:991-999

7. Hammond DC (2008) Postmastectomy reconstruction of the breast using the latissimus dorsi musculocutaneous flap. Cancer $\mathrm{J}$ $14: 248-252$

8. Hernanz F, Regano S, Redondo-Figuero C et al (2007) Oncoplastic breast-conserving surgery: analysis of quadrantectomy and immediate reconstruction with latissimus dorsi flap. World $\mathrm{J}$ Surg 31:1934-1940

9. Spear SL, Boehmler JH, Taylor NS et al (2007) The role of the latissimus dorsi flap in reconstruction of the irradiated breast. Plast Reconstr Surg 119:1-9

10. Bentzen SM, Overgaard M (1993) Early and late normal tissue injury after postmastectomy radiotherapy. Recent Results Cancer Res 130:59-78 
11. Marinus J, Niel CG, de Bie RA et al (2000) Measuring radiation fibrosis: the interobserver reliability of two methods of determining the degree of radiation fibrosis. Int J Radiat Oncol Biol Phys 47:1209-1217

12. Wernicke AG, Rosenblatt R, Rasca M et al (2009) Quantitative assessment of radiation-induced fibrosis of the breast with tissue compliance meter, palpation, and radiological imaging: preliminary results. Breast J 15:583-592

13. Zimmermann JS, Kimmig B (1998) Pharmacological management of acute radiation morbidity. Strahlenther Onkol 174(Suppl 3):62-65

14. Campana F, Zervoudis S, Perdereau B et al (2004) Topical superoxide dismutase reduces post-irradiation breast cancer fibrosis. J Cell Mol Med 8:109-116

15. Gottlober P, Steinert M, Bahren W et al (2001) Interferon-gamma in 5 patients with cutaneous radiation syndrome after radiation therapy. Int J Radiat Oncol Biol Phys 50:159-166
16. Coleman CN, Kelly L, Riese Daly N et al (2002) Phase III study of ibuprofen versus placebo for radiation-induced genitourinary side effects. Int J Radiat Oncol Biol Phys 54:191-194

17. Dion MW, Hussey DH, Doornbos JF et al (1990) Preliminary results of a pilot study of pentoxifylline in the treatment of late radiation soft tissue necrosis. Int J Radiat Oncol Biol Phys 19:401-407

18. Delanian S, Lefaix JL (2004) The radiation-induced fibroatrophic process: therapeutic perspective via the antioxidant pathway. Radiother Oncol 73:119-131

19. Gothard L, Cornes P, Earl J et al (2004) Double-blind placebocontrolled randomised trial of vitamin $\mathrm{E}$ and pentoxifylline in patients with chronic arm lymphoedema and fibrosis after surgery and radiotherapy for breast cancer. Radiother Oncol 73:133-139

20. Feldmeier JJ, Hampson NB (2002) A systematic review of the literature reporting the application of hyperbaric oxygen prevention and treatment of delayed radiation injuries: an evidence based approach. Undersea Hyperb Med 29:4-30 